\title{
Temporal partitioning by felids, dholes and their potential prey in northern Laos
}

\author{
Akchousanh Rasphone ${ }^{1}$ (D) Jan F. Kamler ${ }^{1} \cdot$ David W. Macdonald $^{1}$ \\ Received: 31 March 2020 / Accepted: 23 July 2020 / Published online: 12 August 2020 \\ (C) The Author(s) 2020
}

\begin{abstract}
Temporal partitioning can allow sympatric carnivores to coexist, especially if overlap of other resources is high. Using camera trap data from 2013 to 2017, we investigated the temporal partitioning of a community of wild felids and a canid in Nam Et-Phou Louey National Protected Area, Laos, to determine the extent to which temporal avoidance might be facilitating coexistence of similarly sized carnivores. We also investigated temporal overlap of these carnivore species and their presumed main prey, to determine if their activity is likely most influenced by their prey or potential competitors. The dhole (Cuon alpinus) and clouded leopard (Neofelis nebulosa), the two largest carnivores, had low temporal overlap, and activity appeared to be synchronized with the main prey for dhole, but not clouded leopard. Thus, it was possible that clouded leopard used temporal partitioning to coexist with dhole. The temporal overlap of Asian golden cat (Catopuma temminckii) was high with clouded leopard and moderate with dhole, and overall appeared to be influenced most by its presumed prey species, rather than by its potential competitors. The two small felids had the least temporal overlap between any species, as the marbled cat (Pardofelis marmorata) was primarily diurnal whereas the leopard cat (Prionailurus bengalensis) was primarily nocturnal. Given that the two small felids reportedly have similar diets consisting of small rodents and birds, their temporal partitioning is likely to help facilitate their coexistence. For carnivore species in northern Laos that are most similar in body size and diet, temporal partitioning is likely to be an important mechanism of coexistence. Otherwise, temporal patterns appear to be synchronized with their main prey.
\end{abstract}

Keywords Activity pattern $\cdot$ Asian golden cat $\cdot$ Clouded leopard $\cdot$ Dhole $\cdot$ Lao PDR $\cdot$ Leopard cat $\cdot$ Marbled cat

\section{Introduction}

Species coexistence is one of the most complex topics in ecology (Gordon 2000). In principle, species that are ecologically similar cannot coexist in the same area (Hardin 1960). For such species to coexist, theory anticipates some degree of niche differentiation whereby interspecific competition is reduced (Schoener 1974). Niche differentiation of ecologically similar species may occur in one or more niche dimensions

Communicated by: Krzysztof Schmidt

Electronic supplementary material The online version of this article (https://doi.org/10.1007/s13364-020-00524-9) contains supplementary material, which is available to authorized users.

Akchousanh Rasphone akchousanhr@yahoo.com

1 Wildlife Conservation Research Unit, Department of Zoology, Recanati-Kaplan Centre, University of Oxford, Tubney House, Abingdon Road, Tubney, Abingdon OX13 5QL, UK which include space, time and food (Case and Gilpin 1974; Schoener 1974). In particular, dietary overlap often drives interference competition within carnivore guilds; therefore, food niche differences can be key to successful sympatry (Tsunoda et al. 2017). If dietary partitioning between similarly-sized carnivores is low, then partitioning of other resources is necessary to reduce intraguild predation and facilitate coexistence (Case and Gilpin 1974; Schoener 1974; Holt and Polis 1997). Temporal partitioning has been shown to reduce interference competition and facilitate coexistence among species (Kronfeld-Schor and Dayan 2003;Hayward and Slotow 2009). Additionally, small felids and small canids have been shown to use temporal partitioning to coexist with larger members of their guilds (Kamler et al. 2012b, 2013; Lynam et al. 2013; McCarthy et al. 2015b; Hearn et al. 2018; Santos et al. 2019), especially those with high dietary overlap (Lucherini et al. 2009; Nagy-Reis et al. 2019). However, activity patterns are determined by numerous factors, and often activity patterns of carnivores are driven by the activity of their main prey (Lucherini et al. 2009; Nagy-Reis 
et al. 2019). Understanding the factors that drive the activity patterns of carnivorous species can be important for understanding their ecological niche, especially in regard to their relationships with other carnivores and their main prey.

Nam Et-Phou Louey National Protected Area (hereafter NEPL) in northern Laos is known for its diverse carnivore community (Johnson et al. 2009), yet little is known regarding the ecology of those carnivore species and their ecological interactions. Large carnivores, tiger Panthera tigris and leopard P. pardus, were part of the NEPL community, but they recently became extirpated (Rasphone et al. 2019). Currently, the canid and felid communities of the NEPL consist of large (>15 kg; dhole Cuon alpinus, clouded leopard Neofelis nebulosa), medium (5-15 kg; Asian golden cat Catopuma temminckii), and small-sized ( $<5 \mathrm{~kg}$; marbled cat Pardofelis marmorata, leopard cat Prionailurus bengalensis) species (Table 1). To date, the understanding of the coexistence of this diverse carnivore community is poorly known (Grassman et al. 2005a; Ngoprasert et al. 2012; Lynam et al. 2013; McCarthy et al. 2015b; Hearn et al. 2018; Can et al. 2020). Clearly, more data would better elucidate their mechanisms of coexistence, especially after the extirpation of the largest carnivores, which might have changed the interactions between the remaining carnivores and their prey (Estes et al. 2011; Ripple et al. 2014).

Because competition among carnivores often is driven by diet and body size (Donadio and Buskirk 2006), we assumed that the two most dominant carnivores remaining in NEPL were the dhole and the clouded leopard, which are similar in body size and consume the largest prey (Table 1). Large canids, including dholes and wolves (Canis lupus), live in large packs (Kamler et al. 2015) and behaviourally dominate large felids, such as leopards (Panthera pardus) and pumas (Puma concolor), during encounters due to their numerical advantage (Venkataraman 1995; Ruth et al. 2019). Therefore, dholes likely behaviourally dominate clouded leopards as well. Based on body size, the next most dominant carnivore should be the Asian golden cat, followed by leopard cats and marbled cats (Table 1). Although the activity patterns of these species have been determined in previous studies (Table 1), activity patterns of a species can vary across sites due to differences in numbers of competitors, prey and humans (Valeix et al. 2007; Lucherini et al. 2009; Kamler et al. 2013; Ngoprasert et al. 2017). Regardless, it is not known if the activities of these carnivores are driven by competition within their guild or by their main prey. Better knowledge of the ecological relationships of this carnivore community in NEPL could assist conservation efforts for them, especially given that the IUCN has classified most of these carnivores as threatened or near threatened (Table 1). For example, increased human activities in parks, including tourism, can cause shifts in carnivore activity patterns, which can reduce the health, reproduction and survival of carnivores (Ngoprasert et al. 2017).

We used camera-trap surveys to determine the activity patterns of felid species and dholes in NEPL. Our primary objectives were to determine the temporal overlap between the carnivores, as well as between the carnivores and their potential prey. Based on the body size of these species and their reported diets and activity patterns (Table 1), we made the following predictions: (1) temporal overlap between dholes and clouded leopards will be low, owing to their similarity in diets; (2) temporal overlap between dholes and Asian golden cats will be high, owing to their different dietary niches; (3) temporal overlap between clouded leopards and Asian golden cats will be low, owing to

Table 1 Summary of the reported ecology of the felid and canid community inhabiting the Nam Et-Phou Louey National Protected Area, Laos. The current IUCN status is given after each species $(\mathrm{EN}=$ endangered, $\mathrm{VU}=$ vulnerable, $\mathrm{NT}=$ near threatened, $\mathrm{LC}=$ least concern $)$

\begin{tabular}{lllll}
\hline Species & ${\text { Body size }(\mathrm{kg})^{1}}^{1}$ & Lifestyle $^{1}$ & Activity & Primary prey species \\
\hline Dhole $(\mathrm{EN})^{2}$ & $15-21$ & Terrestrial & Diurnal $^{3}$ & Small, medium and large ungulate $^{4,5}$ \\
${\text { Clouded leopard }(\mathrm{VU})^{6}}^{6}$ & $15-23$ & Semi-arboreal & Nocturnal, crepuscular $^{6}$ & Small ungulate, primate, porcupine, sciurid, bird $^{6}$ \\
${\text { Asian golden cat }(\mathrm{NT})^{7}}^{7}$ & $12-15$ & Terrestrial & Cathemeral, crepuscular $^{7}$ & Small ungulate, murid, sciurid, bird $^{8}$ \\
Leopard cat (LC) $^{9}$ & $3-5$ & Terrestrial & Nocturnal, crepuscular $^{9}$ & Murid, sciurid, bird $^{8}$ \\
Marbled cat (NT) $^{10}$ & $2-4$ & Semi-arboreal & Diurnal, crepuscular $^{10}$ & Murid, sciurid, bird $^{10}$ \\
\hline
\end{tabular}

\footnotetext{
${ }^{1}$ Francis (2019)

${ }^{2}$ Kamler et al. (2015)

${ }^{3}$ Kamler et al. (2012a)

${ }^{4}$ Kamler et al. (2020a)

${ }^{5}$ Thinley et al. (2011)

${ }^{6}$ Grassman et al. (2016)

${ }^{7}$ McCarthy et al. (2015a)

${ }^{8}$ Kamler et al. (2020b)

${ }^{9}$ Ross et al. (2015)

${ }^{10}$ Ross et al. (2016)
} 
similarities in their body size and diet; (4) temporal overlap between Asian golden cats and marbled cats will be higher than the overlap between Asian golden cats and leopard cats, based on results from previous studies; and (5) temporal overlap between leopard cats and marbled cats will be low, owing to their similarity in diets.

\section{Materials and methods}

\section{Study area}

The NEPL is located in the northern highlands of Laos (between latitude $19^{\circ} 50^{\prime}-20^{\circ} 50^{\prime} \mathrm{N}$ and longitude $103^{\circ} 00^{\prime}-103^{\circ}$ $\left.53^{\prime} \mathrm{E}\right)$, bordering Vietnam along its northern boundary (Fig. 1). It covers an area of $5969 \mathrm{~km}^{2}$ with rugged topography across seven districts and three provinces (Houaphan, Luang Prabang and Xiengkhuang) and elevation ranging from 400 to $2257 \mathrm{~m}$, of which $>60 \%$ is above $1000 \mathrm{~m}$ and $91 \%$ with slopes $>12 \%$ (Johnson 2012). Vegetation is dominated by dry evergreen and semi-evergreen forests. However, around one third of the park is degraded forest with a canopy cover of less than $20 \%$. The climate in Laos is tropical monsoonal with a rainy season lasting from May to October, followed by a distinct dry season for the remainder of the year. Annual rainfall ranges from 1400 to $1800 \mathrm{~mm}$ (Johnson 2012). The NEPL is divided into two protected zones; a totally protected zone where human activity (except for protected area management) is prohibited and a peripheral managed use zone where specified livelihood activities are permitted following park regulations (Fig. 1).

\section{Camera trapping}

Systematic camera trap surveys, with clouded leopards as the focal species, were carried out from 2013 to 2017 within the NEPL core zone, in four $\sim 200 \mathrm{~km}^{2}$ blocks (Fig. 1), for a total of 32,027 trap days (Supplementary Data S1). These four sampling blocks are known as Nam Poung-Na Vaen (NPNV), Pha Daeng (PD), Phoupha-Siphou (PS) and Nam Neun (NN; Fig. 1). For each block, camera traps were set in pairs at 80 locations, except for block NN where cameras were set at only 60 locations, with 1$1.5 \mathrm{~km}$ spacing between stations based on the homerange size of clouded leopards (Hearn et al. 2019). We used a mixture of three infrared camera trap models: CuddeBack Ambush IR - Model 1187, Reconyx Hyperfire HC500, and MAGINON - WK 3 HD (Supra Foto-Elektronik-Vertriebs-GmbH).
Fig. 1 The Nam Et-Phou Louey National Protected Area (NEPL), Laos, showing locations of the four survey blocks from 2013 to 2017 (NPNV = Nam Poung-Na Vaen; PD = Pha Daeng; PS = Phoupha-Siphou; NN = Nam Neun). The inset map shows the location of the NEPL in Laos

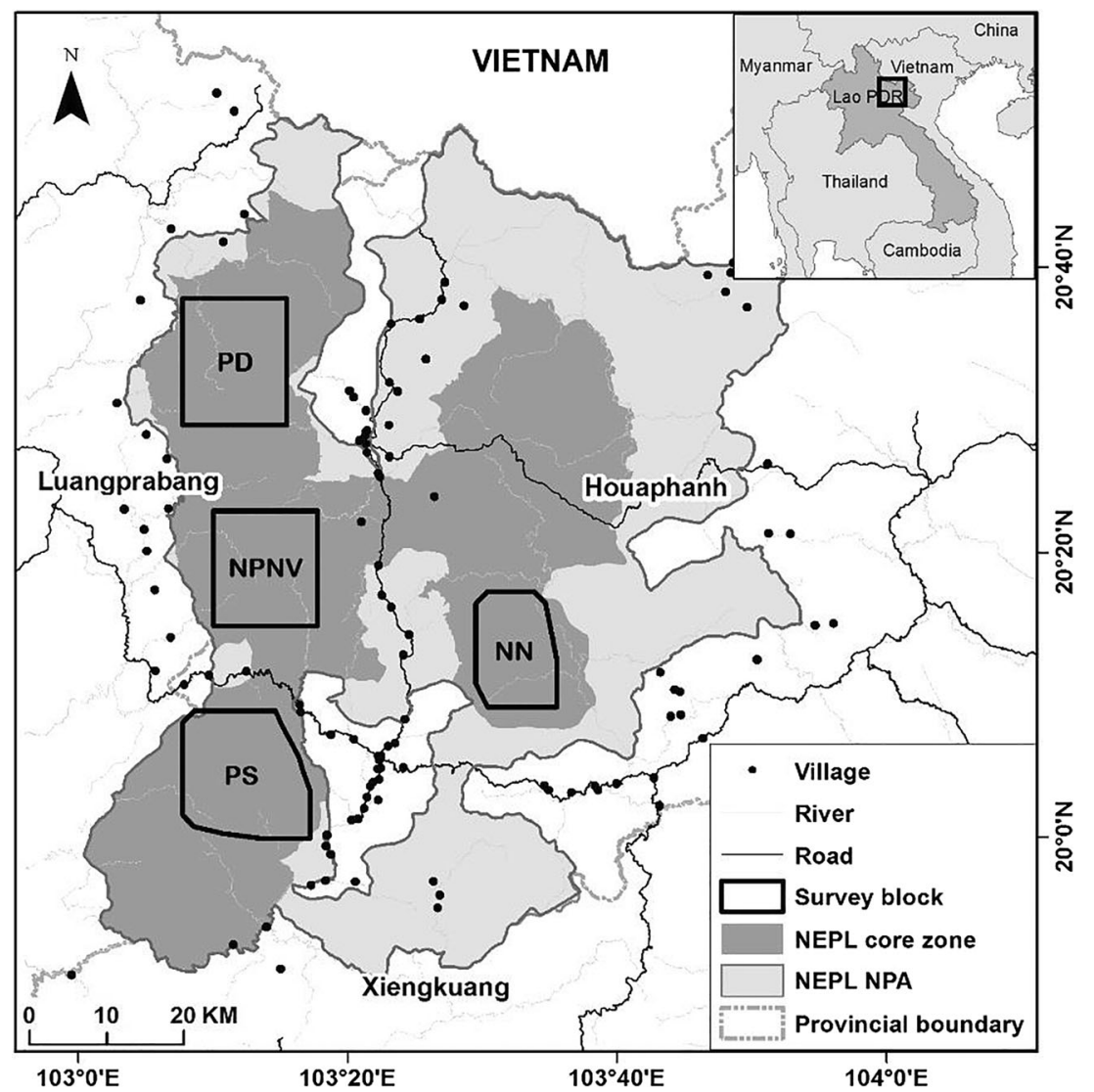


Traps sites were from 629 to $2185 \mathrm{~m}$ altitude (Supplementary Data S1) where $16 \%$ of the sites were below $1000 \mathrm{~m}, 16 \%$ were between 1000 and $1500 \mathrm{~m}$, and $68 \%$ were above $1500 \mathrm{~m}$. About $63 \%$ of the sites were in closed forest, which comprised evergreen and high density semi-evergreen forests. The camera traps were placed mostly along ridge lines and animal trails, and at intersections where trails meet streams. Each camera was mounted onto a tree trunk with its motion beam set at ca. $35 \mathrm{~cm}$ height from the ground at the centre of the trail (approx. shoulder height of an adult clouded leopard). Each survey period lasted for a minimum of 50 days (Supplementary Data S1). Each camera-trap photo of an animal was identified and organised using the CamtrapR (Niedballa et al. 2016). Notionally independent events were considered if they were $>30 \mathrm{~min}$ apart (O'Brien et al. 2003).

\section{Circadian activity and overlap analysis}

Quantitatively investigating activity patterns is challenging because time is a wrapped distribution with an arbitrary zero point; thus, traditional statistical methods cannot be applied (Frey et al. 2017). To solve this, activity patterns can be examined using circular statistics which derive descriptive statistics of temporal data using trigonometric functions (Zar 1996; Frey et al. 2017). Therefore, we used circular statistics to describe activity patterns of carnivores and potential prey in NEPL. Percentage of detections recorded for each hour over a 24-h period was used in the modelling following Ross et al. (2013). Diel activity patterns models were fitted as a function of continuous trigonometric predictors describing one $(\cos \Theta, \sin \Theta)$ and two $(\cos 2 \Theta, \sin 2 \Theta)$ complete cycles in a 24-h period with $\Theta=\pi t / 24$, where $t$ is time in hours (Ross et al. 2013). For $\sin \Theta$, a species is considered crepuscular with a single activity peak either at dawn (if positive coefficient) or dusk (if negative coefficient). For $\cos \Theta$, a species is considered nocturnal with a positive coefficient or diurnal with a negative coefficient. For the bimodal $\sin 2 \Theta$, positive values indicate a species' peak at pre-dawn and pre-dusk whereas negative values indicate activity peaks at post-dawn and post-dusk. For the bimodal $\cos 2 \Theta$, a species is considered crepuscular and active at both dawn and dusk (if negative coefficient) or at both midday and midnight (if positive coefficient). With this approach, activity overlap between paired species was also tested through the construction of models representing the full 24h cycles $(\operatorname{Sin} \Theta, \operatorname{Cos} \Theta, \operatorname{Sin} 2 \Theta, \operatorname{Cos} 2 \Theta)$. An ANOVA test was then conducted for each model to test for significant difference between the activity of each pair of species, and the model with the highest adjusted $R^{2}$ was selected. This analysis was carried out in the R program (R Core Team 2017).

In addition, the kernel density method was implemented to examine the difference in activity pattern between each pair of species (Ridout and Linkie 2009). In the kernel density approach, observed capture times are regarded as random samples from continuous underlying distributions, and a species' time of detection $t$ is the proportion of hours and minutes in 1 day. A measure of overlap under this approach was calculated by fitting non-parametric kernel density functions to the species' diel activity data (Ridout and Linkie 2009; Linkie and Ridout 2011) and was performed using the package overlap_0.3.0 in R (Meredith and Ridout 2014). The coefficient of overlap $(\Delta)$ is calculated as the proportion of overlap between the two species' diel activity curves (Ridout and Linkie 2009). We calculated the coefficients of overlap as a spectrum of proportional values, with 1 indicating complete overlap and 0 indicating no overlap. Schmid and Schmidt (2006) proposed five estimators of $\Delta$, and we used the non-parametric estimator $\Delta_{4}$ because of its superiority for sample sizes that are greater than 50 (Ridout and Linkie 2009; Meredith and Ridout 2014). Following Lynam et al. (2013), values of $\Delta \geq$ 0.70 and $\Delta<0.35$ were defined as a high overlap and a low overlap in diel activity, respectively.

In addition to modelling activity overlap for the selected species pairs, an activity overlap of each selected carnivore species with each of its presumed principle prey species was also modelled. Five ungulate species have been identified as prey species for dhole in NEPL (Kamler et al. 2020a): small dark muntjac ( $M$. rooseveltorum complex), northern red muntjac (Muntiacus vaginalis), sambar (Cervus unicolor), mainland serow (Capricornis milneedwardsii) and Eurasian wild pig (Sus scrofa). For the clouded leopard, a wide range of species have been considered as its potential prey (Table 1), including, in a Lao context, small- and medium-sized ungulates, four species of macaque, two porcupine species, squirrels, ground-dwelling birds and other small birds (Ross et al. 2013; Grassman et al. 2016). For the Asian golden cat, potential prey in NEPL included muntjacs, porcupines, squirrels, ground-dwelling birds, other small birds and rats/mice (Kamler et al. 2020b). The potential prey of the leopard cat and marbled cat are squirrels, birds and rats/mice (Ross et al. 2016; Kamler et al. 2020b). Although the camera-trap survey was designed for the clouded leopard, we assumed that it would accurately record the activity patterns of sympatric carnivores and their potential prey. Although some prey species (e.g. primates) were mostly arboreal, we assumed their ground-level activity detected by the cameras were consistent with their overall activity patterns.

\section{Results}

Of the five carnivore species, the leopard cat had the highest number of notionally independent photographs followed by the Asian golden cat, whereas the marbled cat had the lowest number of independent events (Table 2). Out of the three survey blocks where camera trapping was repeated three times, PD yielded the most notionally independent records for all felids but the fewest for dhole (Table 2). Among the 
Table 2 The number of notionally independent records of felids and dhole, and presumed prey species from each survey block $(\mathrm{NPNV}=$ Nam Poung-Na Vaen; PD = Pha Daeng; PS = Phoupha - Siphou; NN = Nam Neun) in Nam Et-Phou Louey National Protected Area, Laos, 2013-2017

\begin{tabular}{|c|c|c|c|c|}
\hline \multirow[b]{2}{*}{ Species } & \multicolumn{4}{|c|}{ Survey block } \\
\hline & $\mathrm{NN}$ & NPNV & $\mathrm{PD}$ & PS \\
\hline Asian golden cat (Catopuma temminckii) & 8 & 53 & 73 & 38 \\
\hline Clouded leopard (Neofelis nebulosa) & 5 & 34 & 56 & 52 \\
\hline Dhole (Cuon alpinus) & 3 & 67 & 30 & 57 \\
\hline Leopard cat (Prionailurus bengalensis) & 3 & 61 & 79 & 60 \\
\hline Marbled cat (Pardofelis marmorata) & 2 & 45 & 47 & 31 \\
\hline Asiatic brush-tailed porcupine (Atherurus macrourus) & 3 & 93 & 119 & 42 \\
\hline Assamese macaque (Macaca assamensis) & 5 & 18 & 11 & 13 \\
\hline Small dark muntjac(s) (M. rooseveltorum complex.) & 2 & 206 & 210 & 36 \\
\hline East Asian porcupine (Hystrix brachyura) & 17 & 136 & 167 & 70 \\
\hline Eurasian wild pig (Sus scrofa) & 21 & 120 & 147 & 62 \\
\hline Grey peacock pheasant (Polyplectron bicalcaratum) & 8 & 40 & 187 & 22 \\
\hline Indochinese serow (Capricornis milneedwardsii) & 7 & 128 & 107 & 32 \\
\hline Northern pig-tailed macaque (Macaca leonina) & - & 3 & 1 & 10 \\
\hline Red junglefowl (Gallus gallus) & 7 & 18 & 105 & 17 \\
\hline Northern red muntjac (Muntiacus vaginalis) & 83 & 489 & 629 & 292 \\
\hline Red-cheeked squirrel (Dremomys rufigenis) & - & 5 & 26 & 28 \\
\hline Rhesus macaque (Macaca mulatta) & 5 & 6 & 13 & 15 \\
\hline Sambar (Cervus unicolor) & 4 & 98 & 29 & 45 \\
\hline Silver pheasant (Lophura nycthemera) & 12 & 81 & 74 & 59 \\
\hline Stump-tailed macaque (Macaca arctoides) & 81 & 385 & 457 & 37 \\
\hline Birds spp. & 3 & 66 & 73 & 49 \\
\hline Rat/mouse spp. (Muridae) & 8 & 78 & 134 & 191 \\
\hline Squirrels spp. (Sciuridae) & 2 & 26 & 108 & 46 \\
\hline
\end{tabular}

presumed prey species, the northern red muntjac had the most records in all blocks, followed by the stump-tailed macaque Macaca arctoides. Three out of four species of macaques detected during the study had fewer than 50 notionally independent records, which were relatively low compared with those of all other prey species (Table 2), presumably because of the greater arboreality of the macaque species.

\section{Circadian activity}

There was strong evidence that activity patterns differed among the five carnivore species $\left(\operatorname{Cos} \Theta^{*}\right.$ Species: $F_{95}=$ 14.78, $P<0.001$; $\operatorname{Sin} \Theta^{*}$ Species: $\left.F_{95}=3.22, P=0.01\right)$. The dhole showed a strongly diurnal and crepuscular (both dawn and dusk) pattern of activity, with the highest peak of activity at dusk (Table 3; Fig. 2a). The clouded leopard was strongly crepuscular, but most active at dawn (Table 3; Fig. 2a). The Asian golden cat was active both by day and by night (Fig. 2b) but with a peak of activity at dawn (Table 3 ). The leopard cat was clearly nocturnal while the marbled cat was strongly diurnal with some activity at dawn and dusk (Table 3; Fig. 2f).

\section{Diel activity overlap between carnivores}

The results from the wave analysis showed that there was a difference in activity within each pair of species (best models of most pairs were $P<0.05$; Table 4). The activity overlap between dhole and clouded leopard (0.51 $\Delta_{4}$; Fig. 2a) was slightly lower than that between dhole and Asian golden cat $(0.66$ $\Delta_{4}$; Fig. 2b). Although our wave analysis suggested significant difference in $\operatorname{Cos} 2 \Theta(P=0.038)$ between clouded leopard and Asian golden cat, the $\operatorname{Sin} \Theta$ was not significant $(P=0.753$; Table 4$)$. This indicated a high level of overlap between the clouded leopard and the Asian golden cat, a result consistent with the kernel density analysis which also indicated a strong overlap in activity between them $\left(0.80 \Delta_{4}\right.$; Fig. $\left.2 \mathrm{c}\right)$. We found that activity overlap between the Asian golden cat and the marbled cat was much higher than the overlap between the Asian golden cat and the leopard cat $\left(0.74 \Delta_{4}\right.$ and $0.55 \Delta_{4}$; Fig. 2e, d). Notably, the leopard cat and the marbled cat had the lowest overlap in activity between any two carnivore species (0.31 $\Delta_{4}$; Fig. $\left.2 \mathrm{f}\right)$. 
Table 3 Estimates of coefficients ( \pm SE) of diel activity models and best models with adjusted $R^{2}$ values for five carnivore species $(\mathrm{D}=$ dhole; $\mathrm{CL}=$ clouded leopard $\mathrm{AC}=$ Asian golden cat $\mathrm{LC}=$ leopard cat $\mathrm{MC}=$ marbled cat) in Nam Et-Phou Louey National Protected Area, Laos, 2013-2017. Significant values are designated with $* P<0.05$, $* * P<0.01$, and $* * * P<0.001$

\begin{tabular}{|c|c|c|c|c|c|c|}
\hline & $\operatorname{Sin} \Theta^{1}$ & $\operatorname{Cos} \Theta^{2}$ & $\operatorname{Sin} 2 \Theta^{3}$ & $\operatorname{Cos} 2 \Theta^{4}$ & Best model & Adjusted $R^{2}$ \\
\hline $\mathrm{D}$ & $0.009 \pm 0.005$ & $-0.023 \pm 0.005 * * *$ & $0.006 \pm 0.005$ & $-0.017 \pm 0.005^{* *}$ & $\operatorname{Cos} \Theta+\operatorname{Cos} 2 \Theta$ & 0.533 \\
\hline CL & $0.035 \pm 0.005 * * *$ & $0.006 \pm 0.005$ & $-0.004 \pm 0.005$ & $-0.021 \pm 0.005 * * *$ & $\operatorname{Sin} \Theta+\operatorname{Cos} 2 \Theta$ & 0.737 \\
\hline $\mathrm{AC}$ & $0.025 \pm 0.006^{* * *}$ & $-0.002 \pm 0.006$ & $-0.003 \pm 0.006$ & $-0.002 \pm 0.006$ & $\operatorname{Sin} \Theta$ & 0.413 \\
\hline $\mathrm{LC}$ & $0.008 \pm 0.006$ & $0.031 \pm 0.006^{* * *}$ & $0.002 \pm 0.006$ & $-0.002 \pm 0.006$ & $\operatorname{Cos} \Theta$ & 0.495 \\
\hline $\mathrm{MC}$ & $0.019 \pm 0.008^{*}$ & $-0.030 \pm 0.008^{* * *}$ & $-0.009 \pm 0.008$ & $-0.020 \pm 0.008 *$ & $\operatorname{Sin} \Theta+\operatorname{Cos} \Theta+\operatorname{Cos} 2 \Theta$ & 0.506 \\
\hline
\end{tabular}

${ }^{1}$ For $\sin \Theta$, a species is considered crepuscular with a single activity peak either at dawn (if positive coefficient) or dusk (if negative coefficient). ${ }^{2}$ For $\cos \Theta$, a species is considered nocturnal with a positive coefficient or diurnal with a negative coefficient

${ }^{3}$ For the bimodal $\sin 2 \Theta$, positive values indicate a species' peak at pre-dawn and pre-dusk whereas negative values indicate activity peaks at post-dawn and post-dusk

${ }^{4}$ For the bimodal $\cos 2 \Theta$, a species is considered crepuscular and active at both dawn and dusk (if negative coefficient) or at both midday and midnight (if positive coefficient)

\section{Diel activity overlap between carnivores and their prey}

Dhole activity overlapped most strongly with the dark muntjac $\left(0.85 \Delta_{4}\right)$ and the Eurasian wild pig $\left(0.80 \Delta_{4}\right)$. While both prey species were strongly diurnal, there was a peak of activity of the dark muntjac at dusk, closely corresponding to the activity of the dhole (Supplementary Data S2.1a). Overall, the overlap coefficients between the clouded leopard and their candidate prey species were greater than $0.40 \Delta_{4}$ (Supplementary Data S2.2). The strongest overlaps were between the clouded leopard and (i) sambar and (ii) Indochinese serow $\left(0.79 \Delta_{4}\right.$ and $0.75 \Delta_{4}$, respectively). Clouded leopard overlapped most with the prey species that had an activity peak at dawn.

The Asian golden cat's activity overlapped strongly with that of both types of muntjacs, squirrels and all listed bird species (with overlap coefficients $>0.70 \Delta_{4}$; Supplementary Data S2.3); these overlaps were more strongly congruent than those revealed for clouded leopard and their candidate prey species. Asian golden cat overlapped most with prey that were active by day, and it overlapped little with porcupines ( 0.45 $\left.\Delta_{4}\right)$ and rats/mice $\left(0.42 \Delta_{4}\right)$. Insofar as rats/mice were strongly nocturnal, these prey species overlapped strongly with leopard cat $\left(0.84 \Delta_{4}\right.$; Supplementary Data S2.4f). The marbled cat overlapped most strongly with candidate prey that were more diurnal such as squirrels and birds (with overlap coefficients > 0.70; Supplementary Data S2.5a - e).

\section{Discussion}

Temporal partitioning among carnivores in NEPL was exhibited only between species that were similar in body size, and likely had similar diets. Otherwise, the activity of carnivores appeared to be synchronized with that of their main prey. Thus, our research supports previous studies that showed temporal partitioning can reduce interference competition and facilitate coexistence among carnivores, especially those with high dietary overlap (Kronfeld-Schor and Dayan 2003; Hayward and Slotow 2009; Lucherini et al. 2009; NagyReis et al. 2019). For example, the temporal overlap was low between dholes and clouded leopards, which supported our prediction, indicating temporal partitioning occurred between these species. Dholes were mostly diurnal with a peak of activity at dusk, which is consistent with findings elsewhere (Grassman et al. 2005b; Kawanishi and Sunquist 2008; Kamler et al. 2012a; Bashir et al. 2014). Dhole activity overlapped moderately to strongly with both muntjac species. Previous research in NEPL and elsewhere in Southeast Asia showed that muntjacs were the most preferred prey of dholes regardless of ungulate diversity and densities (Kamler et al. 2020a), indicating that the activity of dholes was driven by the activity of their most preferred prey. Clouded leopard activity was crepuscular with a peak at dawn, similar to that observed in some areas (Azlan and Sharma 2006; Lynam et al. 2013; McCarthy et al. 2015b), but not others (Singh and Macdonald 2017; Hearn et al. 2018; Mukherjee et al. 2019; Can et al. 2020). Although clouded leopard activity synchronised with that of the Indochinese serow and sambar, it is doubtful that these two species are preferred prey of clouded leopards, given the large body size of these ungulates relative to that of clouded leopards. Instead, the preferred prey of clouded

Fig. 2 Overlap in temporal activity between (a) dhole and clouded leopard, (b) dhole and Asian golden cat, (c) clouded leopard and Asian golden cat, (d) Asian golden cat and leopard cat, (e) Asian golden cat and marbled cat, and (f) leopard cat and marbled cat in Nam Et-Phou Louey National Protected Area, Laos (2013-2017), as measured by the kernel density across the 24-h period 
(a) Dhole vs. Clouded leopard $(\Delta 4=0.51 ; \mathrm{CI}=0.39-0.57)$

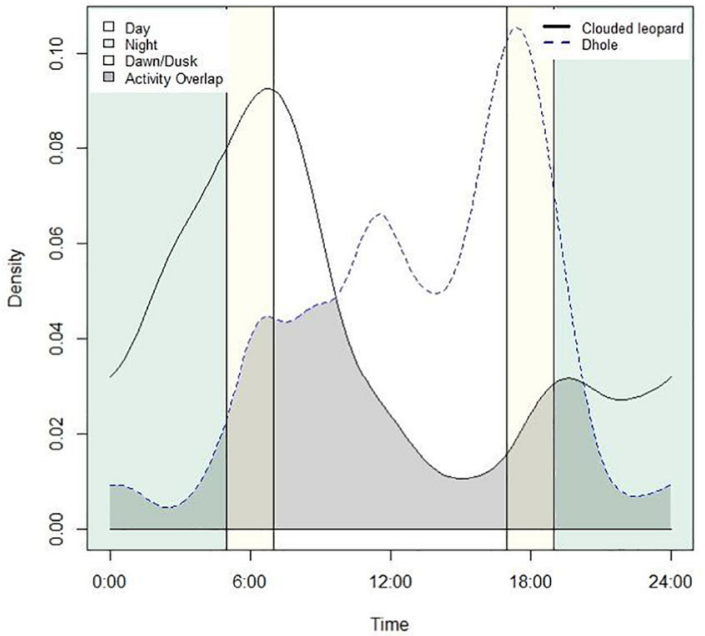

(c) Clouded leopard vs. Asian golden cat $(\Delta 4=0.80 ; \mathrm{CI}=0.68-0.86)$

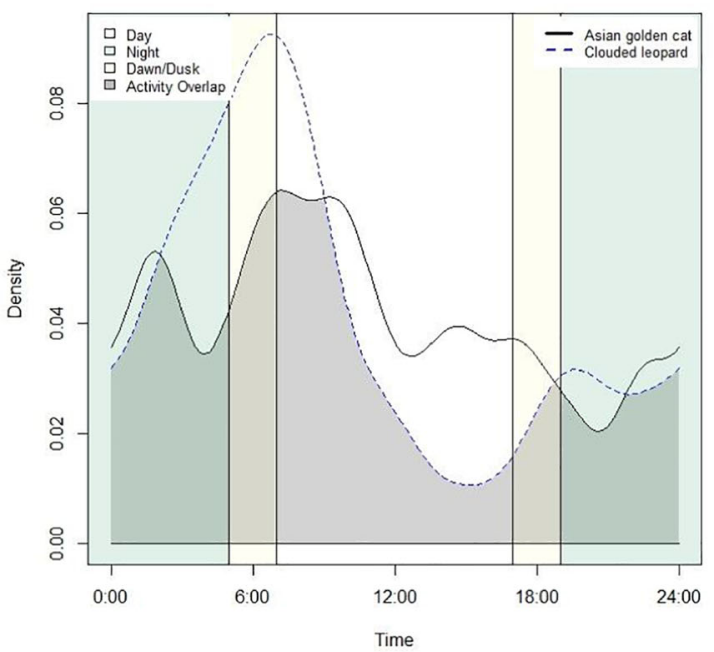

(e) Asian golden cat vs. Marbled cat $(\Delta 4=0.74 ; \mathrm{CI}=0.65-0.81)$

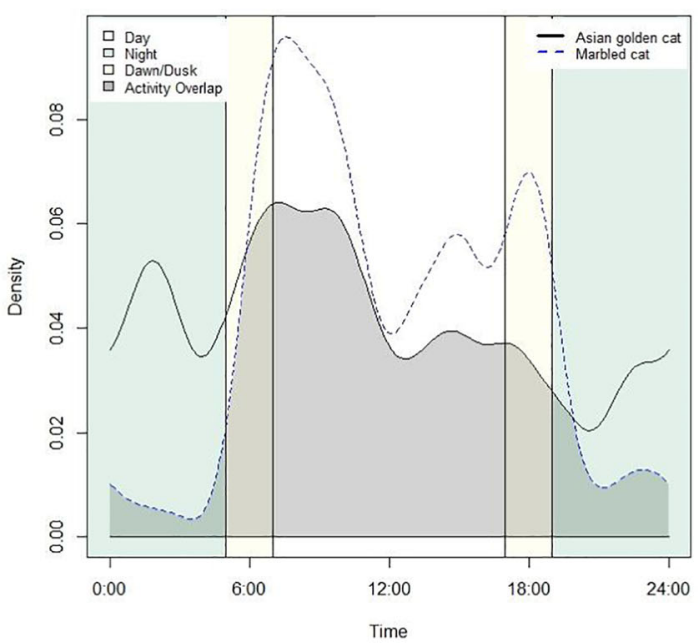

(b) Dhole vs. Asian golden cat $(\Delta 4=0.66$; $\mathrm{CI}=0.55-0.74)$

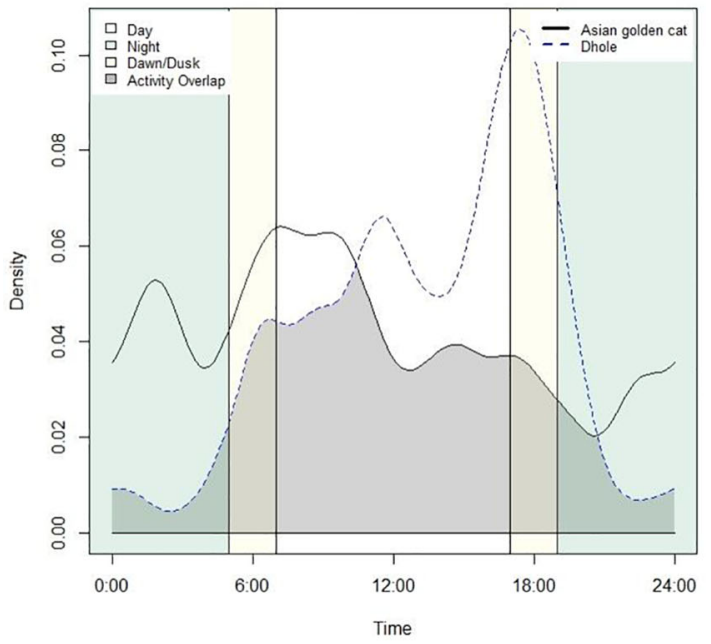

(d) Asian golden cat vs Leopard cat $(\Delta 4=0.55$; $C I=0.43-0.60)$

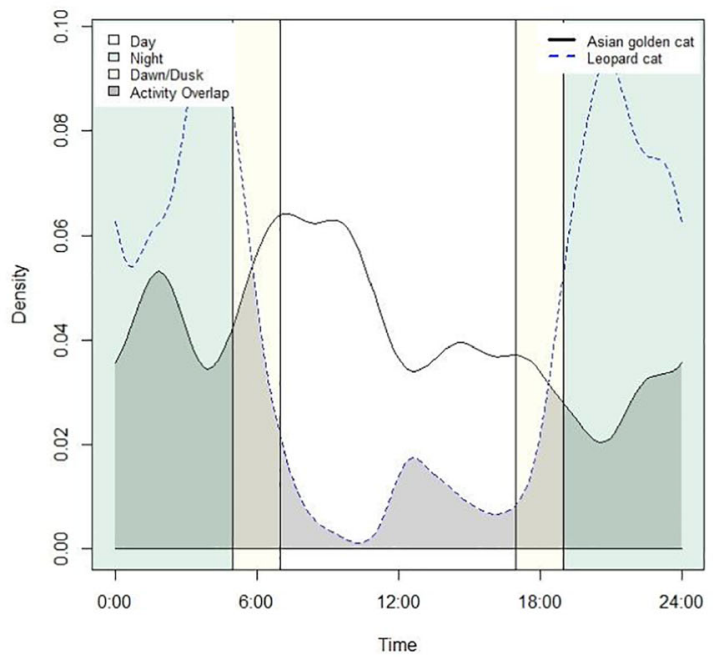

(f) Leopard cat vs. Marbled cat $(\Delta 4=0.31 ; \mathrm{CI}=0.20-0.33)$

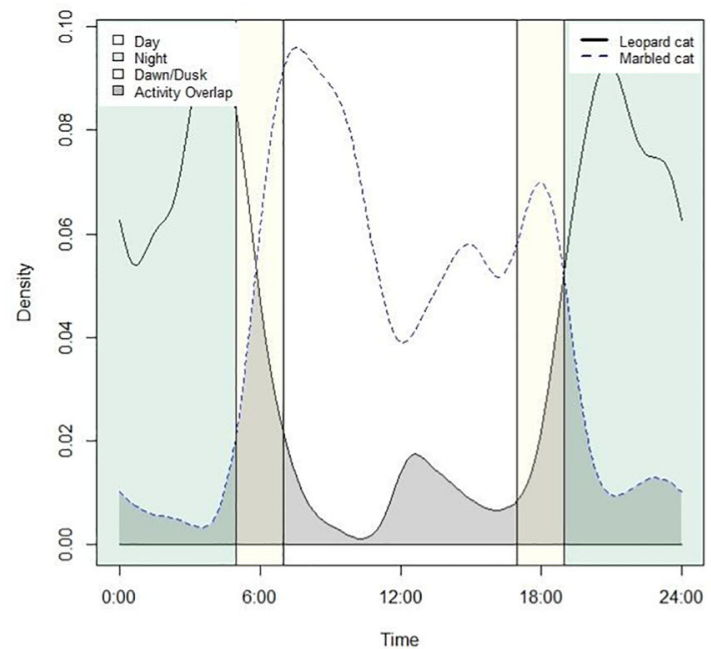


Table 4 Overlap estimates between carnivore species calculated from the kernel density (correlation coefficient $\Delta_{4}$ ), and significant wave(s) of best models for the interactions, from cameratrap data collected in Nam EtPhou Louey National Protected Area, Laos, 2013-2017. The $P(t)$ represents the $P$ value with the associated test statistic $(t)$ in parentheses; $P<0.05$ indicate that species differ in the corresponding wave

\begin{tabular}{lllll}
\hline Species pairing & Kernel density $\left(\Delta_{4}\right)$ & Wave & Adjusted $R^{2}$ & $P(t)$ \\
\hline Dhole-clouded leopard & 0.51 & $\operatorname{Sin} \Theta$ & 0.525 & $0.009(-2.919)$ \\
& & $\operatorname{Cos} \Theta$ & & $0.046(-2.145)$ \\
Dhole-Asian golden cat & 0.66 & $\operatorname{Sin} \Theta$ & 0.604 & $0.010(-2.874)$ \\
& & $\operatorname{Cos} \Theta$ & & $0.046(-2.144)$ \\
Clouded leopard-Asian golden cat & 0.80 & $\operatorname{Sin} \Theta$ & 0.682 & $0.753(-0.319)$ \\
& & $\operatorname{Cos} 2 \Theta$ & & $0.038(-2.233)$ \\
Asian golden cat-leopard cat & 0.55 & $\operatorname{Sin} \Theta$ & 0.722 & $0.044(-2.161)$ \\
& & $\operatorname{Cos} \Theta$ & & $<0.001(4.992)$ \\
Asian golden cat-marbled cat & 0.74 & $\operatorname{Sin} \Theta$ & 0.475 & $0.278(-1.117)$ \\
& & $\operatorname{Cos} \Theta$ & & $0.076(-1.883)$ \\
Leopard cat-marbled cat & 0.31 & $\operatorname{Cos} \Theta$ & 0.366 & $0.002(-3.540)$ \\
& & $\operatorname{Cos} 2 \Theta$ & & $0.372(-0.915)$ \\
\hline
\end{tabular}

leopards is most likely smaller prey species such as muntjacs and primates (Table 1), although activity overlap with these prey species was low. Therefore, we conclude that activity of clouded leopards was most influenced by avoidance of dholes, rather than prey, likely because the pack-living dholes are behaviorally dominant over clouded leopards.

The activity pattern of the only meso-carnivore in NEPL, the Asian golden cat, was crepuscular with activity intensified from dawn until midmorning. Based on the kernel density activity plot, the species seemed to be active both day and night, which is consistent with previous studies (Kawanishi and Sunquist 2008; Johnson et al. 2009; Lynam et al. 2013; Singh and Macdonald 2017; Haidir et al. 2018; Mukherjee et al. 2019). Its temporal overlap with the dhole was moderate, which did not support our prediction that these two species should have high activity overlap. In NEPL, the Asian golden cat was found to have a high dietary niche breadth and broad diet, which consisted mostly of muntjacs, murids and other rodents (Kamler et al. 2020b). The activity of Asian golden cats had moderate overlap with both muntjac species, squirrels and birds, indicating that the activity of this species was driven by prey rather than avoidance of dholes. Indeed, the cathemeral activity of Asian golden cats may have been due to the diversity of their prey, which includes some species that were active during the day (e.g. muntjacs, squirrels, birds) and other prey species that were active at night (e.g. murids). Although both dholes and Asian golden cats consumed muntjac in NEPL (Kamler et al. 2020a, b), the Asian golden cat consumed less muntjac and much larger quantities of smaller prey compared to dholes, indicating that there was little competition for food resources. Therefore, the diversity of both small and large prey, and both diurnal and nocturnal prey, in the diet of Asian golden cats likely facilitated their coexistence with dholes without the need for temporal partitioning. Overall, cathemerality and diversity in diet may enable the Asian golden cat to fit flexibly into the Southeast Asian felid and canid guild.
Clouded leopards and Asian golden cats had similar activity patterns, which did not support our prediction that they should exhibit temporal partitioning. Our results were similar to that found in Sumatra, where Sunda clouded leopards (Neofelis diardi) and Asian golden cats had high temporal overlap (McCarthy et al. 2015b). McCarthy et al. (2015b) speculated that differences in resource exploitation due to the clouded leopard's greater arboreality facilitated their coexistence with Asian golden cats. Additionally, the significantly greater canine length in clouded leopards suggests that they have a vastly different predatory niche (Nowell and Jackson 1996; Sunquist and Sunquist 2002), with clouded leopards feeding primarily on primates and small ungulates and Asian golden cat feeding primarily on small rodents and some small ungulates. We conclude that the differences in lifestyle and canine length result in significantly different dietary niches between clouded leopards and Asian golden cats, which facilitated their coexistence without the need for temporal partitioning.

The activity patterns of the Asian golden cat overlapped more with those of the marbled cat than with those of the leopard cat, which supported our prediction. We found that the marbled cat was primarily diurnal which is consistent with that reported in previous studies (Johnson et al. 2009; Lynam et al. 2013; Sunarto et al. 2015; Mukherjee et al. 2019; Singh and Macdonald 2017; Hearn et al. 2018). In NEPL, the activity of marbled cats coincided with the activity of avian and arboreal prey, indicating their activity pattern was driven by that of their main prey. The marbled cat and Asian golden cat likely have different dietary niches, especially given that the Asian golden cat is about 3 times larger in body size than the marbled cat, and that the marbled cat is more arboreal than the Asian golden cat. Consequently, temporal partitioning apparently is not necessary to facilitate their coexistence. The Asian golden cat and leopard cat had low activity overlap, primarily because the leopard cat was strongly nocturnal, similar to that reported in previous studies (Johnson et al. 2009; Lynam et al. 2013; Sunarto et al. 2015; Singh and 
Macdonald 2017; Hearn et al. 2018; Mukherjee et al. 2019; Can et al. 2020). The nocturnal activity of the leopard cat is likely adapted to coincide with their main prey, which is predominantly murids (Kamler et al. 2020b). Thus, although leopard cats and Asian golden cats in NEPL were found to have moderate overlap in diets because of the consumption of small rodents (Kamler et al. 2020b), temporal partitioning likely helped to facilitate their coexistence.

Leopard cats and marbled cats had low activity overlap, which supported our prediction that they should exhibit temporal partitioning. It is likely that two felid species so similar in body size likely partition other resources as well, such as diets. For example, marbled cats are more arboreal than leopard cats; thus, the former likely feeds more on arboreal species, such squirrels and birds, which are diurnal. In contrast, leopard cats prey primarily on nocturnal murids (Kamler et al. 2020b), which would facilitate dietary partitioning. We conclude that activity patterns of leopard cats and marbled cats are driven by their main prey, rather than competition, and that differences in the activity of their presumed main prey facilitates temporal partitioning and coexistence between these two small felids.

Our camera trapping study was large-scale, repeated and robust, but we lacked spatial and complete dietary data to frame the interpretation of our results. Additionally, our data were collected during the dry season, so we cannot comment on whether temporal activity differed in the wet season. Furthermore, tigers and leopards were recently extirpated from NEPL (Rasphone et al. 2019); therefore, it is not known what, if any, impacts these two apex carnivores would have on the activity patterns of the remaining species. In NEPL, coexistence among similarly sized carnivores was facilitated by temporal partitioning, and differences in social organization, morphology and arboreality likely contributed to different dietary niches, which further facilitated coexistence. Overall, several different niche dimensions apparently were partitioned among these carnivore species, which is consistent with the principles of niche differentiation (Case and Gilpin 1974; Schoener 1974). Future research should determine other aspects of niche partitioning among these species, including dietary and spatial overlap. Future research also should investigate the community-level effects of tigers and leopards, as well as different densities of prey, on the niche partitioning among carnivores. Such information, which is rather difficult to obtain in the tropical forests of Southeast Asia, would further elucidate the complete set of mechanisms that allow such a diverse carnivore community to coexist, and how those mechanisms might change under various environmental conditions.

Acknowledgements We thank the Wildlife Conservation Society and the Nam Et-Phou Louey National Protected Area for their extensive in-kind support. We further thank Phonesouk Chanthalavong for his assistance and Lucy Talents for her guidance.
Funding information This study was supported by an Exploration Grant to AR from the National Geographic and a grant to DWM from the Robertson Foundation.

Open Access This article is licensed under a Creative Commons Attribution 4.0 International License, which permits use, sharing, adaptation, distribution and reproduction in any medium or format, as long as you give appropriate credit to the original author(s) and the source, provide a link to the Creative Commons licence, and indicate if changes were made. The images or other third party material in this article are included in the article's Creative Commons licence, unless indicated otherwise in a credit line to the material. If material is not included in the article's Creative Commons licence and your intended use is not permitted by statutory regulation or exceeds the permitted use, you will need to obtain permission directly from the copyright holder. To view a copy of this licence, visit http://creativecommons.org/licenses/by/4.0/.

\section{References}

Azlan JM, Sharma DSK (2006) The diversity and activity patterns of wild felids in a secondary forest in Peninsular Malaysia. Oryx 40:36-41. https://doi.org/10.1017/s0030605306000147

Bashir T, Bhattacharya T, Poudyal K, Roy M, Sathyakumar S (2014) Precarious status of the endangered dhole Cuon alpinus in the high elevation Eastern Himalayan habitats of Khangchendzonga Biosphere Reserve, Sikkim, India. Oryx 48:125-132

Can ÖE, Yadav BP, Johnson PJ, Ross J, D'Cruze N, Macdonald DW (2020) Factors affecting the occurrence and activity of clouded leopards, common leopards and leopard cats in the Himalayas. Biodivers Conserv 29:839-851

Case TJ, Gilpin ME (1974) Interference competition and niche theory. Proc Natl Acad Sci U S A 71:3073-3077

Core Team R (2017) R: A language and environment for statistical computing. R Foundation for Statistical Computing, Vienna

Donadio E, Buskirk SW (2006) Diet, morphology, and interspecific killing in carnivora. Am Nat 167:524-536

Estes JA, Terborgh J, Brashares JS et al (2011) Trophic downgrading of planet earth. Science 333:301-306. https://doi.org/10.1126/science. 1205106

Francis CM (2019) Field guide to the mammals of South-east Asia, 2nd edition. Bloomsbury Wildlife. N Y

Frey S, Fisher JT, Burton AC, Volpe JP (2017) Investigating animal activity patterns and temporal niche partitioning using camera-trap data: challenges and opportunities. Remote Sens Ecol Conserv 3: $123-132$

Gordon CE (2000) The coexistence of species. Rev. Chil Hist Nat 73: 175-198

Grassman LI, Tewes ME, Silvy NJ, Kreetiyutanont K (2005a) Ecology of three sympatric felids in a mixed evergreen forest in north-central Thailand. J Mammal 86:29-38

Grassman LI, Tewes ME, Silvy NJ, Kreetiyutanont K (2005b) Spatial ecology and diet of the dhole Cuon alpinus (Canidae, Carnivora) in north central Thailand. Mammalia 69:11-20. https://doi.org/10. 1515/mamm.2005.002

Grassman L, Lynam A, Mohamad S et al (2016) Neofelis nebulosa. The IUCN Red List of Threatened Species 2016:E. T14519A9721509. https://doi.org/10.2305/IUCN.UK.2016-1.RLTS. T14519A97215090.en. Accessed 10 Jan 2020

Haidir IA, Macdonald DW, Linkie M (2018) Assessing the spatiotemporal interactions of mesopredators in Sumatra's tropical rainforest. 
PLoS ONE 13:e0202876. https://doi.org/10.1371/journal.pone. 0202876

Hardin G (1960) The competitive exclusion principle. Science 131:12921297

Hayward MW, Slotow R (2009) Temporal partitioning of activity in large African carnivores: tests of multiple hypotheses. Afr J Wildl Res 39: $109-125$

Hearn AJ, Cushman SA, Ross J, Goossens B, Hunter LT, Macdonald DW (2018) Spatio-temporal ecology of sympatric felids on Borneo. Evidence for resource partitioning? PLoS ONE 13:e0200828

Hearn AJ, Ross J, Bernard H et al (2019) Responses of Sunda clouded leopard Neofelis diardi population density to anthropogenic disturbance: refining estimates of its conservation status in Sabah. Oryx 53:643-653

Holt RD, Polis GA (1997) A theoretical framework for intraguild predation. Am Nat 149:745-764

Johnson A (2012) A landscape summary for the Nam Et-Phou Louey National Protected Area, Lao PDR. In: Sunderland TCH, Sayer J, Minh-Ha H (eds) Evidence-based conservation: lessons from the lower Mekong. Earthscan, London

Johnson A, Vongkhamheng C, Saithongdam T (2009) The diversity, status and conservation of small carnivores in a montane tropical forest in northern Laos. Oryx 43:626-633. https://doi.org/10.1017/ s0030605309990238

Kamler JF, Johnson A, Vongkhamheng C, Bousa A (2012a) The diet, prey selection, and activity of dholes (Cuon alpinus) in northern Laos. J Mammal 93:627-633. https://doi.org/10.1644/11-Mamma-241.1

Kamler JF, Stenkewitz U, Klare U, Jacobsen NF, Macdonald DW (2012b) Resource partitioning among cape foxes, bat-eared foxes, and black-backed jackals in South Africa. J Wildl Manag 76:12411253

Kamler JF, Stenkewitz U, Macdonald DW (2013) Lethal and sublethal effects of black- backed jackals on cape foxes and bat-eared foxes. J Mammal 94:295-306

Kamler JF, Songsasen N, Jenks K, Srivathsa A, Li S, Kunkel K (2015) Cuon alpinus. The IUCN Red List of Threatened Species 2015: E.T5953A72477893. https://doi.org/10.2305/IUCN.UK.2015-4. RLTS.T5953A72477893.en. Accessed 10 Jan 2020

Kamler JF, Thatdokkham K, Rostro-García S et al (2020a) Diet and prey selection of dholes in evergreen and deciduous forests of Southeast Asia. J Wildl Manage 84:In press

Kamler JF, Inthapanya X, Rasphone A et al (2020b) Diet, prey selection, and activity of Asian golden cats and leopard cats in northern Laos. J Mammal 101:In press

Kawanishi K, Sunquist ME (2008) Food habits and activity patterns of the Asiatic golden cat (Catopuma temminckii) and dhole (Cuon alpinus) in a primary rainforest of Peninsular Malaysia. Mammal Stud 33:173-177

Kronfeld-Schor N, Dayan T (2003) Partitioning of time as an ecological resource. Annu Rev. Ecol Evol Syst 34:153-181. https://doi.org/10. 1146/annurev.ecolsys.34.011802.132435

Linkie M, Ridout MS (2011) Assessing tiger-prey interactions in Sumatran rainforests. J Zool 284:224-229

Lucherini M, Reppucci JI, Walker RS et al (2009) Activity pattern segregation of carnivores in the high Andes. J Mammal 90:1404-1409

Lynam AJ, Jenks KE, Tantipisanuh N et al (2013) Terrestrial activity patterns of wild cats from camera-trapping. Raffles Bull Zool 61: 407-415

McCarthy J, Dahal S, Dhendup T et al (2015a) Catopuma temminckii. The IUCN Red List of Threatened Species 2015: E.T4038A97165437. https://doi.org/10.2305/IUCN.UK.2015-4. RLTS.T4038A97165437.en. Accessed 10 Jan 2020
McCarthy JL, Wibisono HT, McCarthy KP, Fuller TK, Andayani N (2015b) Assessing the distribution and habitat use of four felid species in Bukit Barisan Selatan National Park, Sumatra, Indonesia. Glob Ecol Conserv 3:210-221. https://doi.org/10.1016/j.gecco. 2014.11.009

Meredith M, Ridout M (2014) Overview of the overlap package. R Proj: $1-9$

Mukherjee S, Singh P, Silva AP et al (2019) Activity patterns of the small and medium felid (Mammalia: Carnivora: Felidae) guild in northeastern India. J Threat Taxa 11:13432-13,447

Nagy-Reis MB, Iwakami VHS, Estevo CA, Setz EZF (2019) Temporal and dietary segregation in a neotropical small-felid assemblage and its relation to prey activity. Mamm Biol 95:1-8

Ngoprasert D, Lynam AJ, Sukmasuang R et al (2012) Occurrence of three felids across a network of protected areas in thailand: Prey, Intraguild, and Habitat Associations. Biotropica 44:810-817. https://doi.org/10.1111/j.1744-7429.2012.00878.x

Ngoprasert D, Lynam AJ, Gale GA (2017) Effects of temporary closure of a national park on leopard movement and behaviour in tropical Asia. Mamm Biol 82:65-73

Niedballa J, Sollmann R, Courtiol A, Wilting A (2016) camtrapR: an R package for efficient camera trap data management. Methods Ecol Evol 7:1457-1462

Nowell K, Jackson P (1996) Wild cats: status survey and conservation action plan. IUCN/SSC action plans for the conservation of biological diversity. IUCN, Gland, Switzerland

O'Brien TG, Kinnaird MF, Wibisono HT (2003) Crouching tigers, hidden prey: Sumatran tiger and prey populations in a tropical forest landscape. Anim Conserv 6:131-139. https://doi.org/10.1017/ S1367943002003172

Rasphone A, Kéry M, Kamler J, Macdonald D (2019) Documenting the demise of tiger and leopard, and the status of other carnivores and prey, in Lao PDR's most prized protected area: Nam Et-Phou Louey. Glob Ecol Conserv 20:e00766

Ridout MS, Linkie M (2009) Estimating overlap of daily activity patterns from camera trap data. J Agric Biol Environ Stat 14:322-337

Ripple WJ, Estes JA, Beschta RL et al (2014) Status and ecological effects of the world's largest carnivores. Science 343:1241484

Ross J, Hearn AJ, Johnson PJ, Macdonald DW (2013) Activity patterns and temporal avoidance by prey in response to Sunda clouded leopard predation risk. J Zool 290:96-106

Ross J, Brodie J, Cheyne S et al (2015) Prionailurus bengalensis. The IUCN Red List of Threatened Species 2105:e.T18146A50661611. https://doi.org/10.2305/IUCN.UK.2016-1.RLTS. T18146A50661611.en. Accessed 10 Jan 2020

Ross J, Brodie J, Cheyne S et al (2016) Pardofelis marmorata. The IUCN Red List of Threatened Species 2016:e.TI6218A97164299. https:// doi.org/10.2305/IUCN.UK.2016-1.RLTS.TI6218A97164299.en. Accessed 10 Jan 2020

Ruth TK, Buotte PC, Hornocker MG (2019) Yellowstone cougars: ecology before and during wolf restoration. University Press of Colorado, Louisville

Santos F, Carbone C, Wearn OR et al (2019) Prey availability and temporal partitioning modulate felid coexistence in Neotropical forests. PLoS ONE 14:e0213671

Schmid F, Schmidt A (2006) Nonparametric estimation of the coefficient of overlapping - theory and empirical application. Comput Stat Data Anal 50:1583-1596

Schoener TW (1974) Resource Partitioning in Ecological Communities. Science 185:27-39. https://doi.org/10.1126/science.185.4145.27

Singh P, Macdonald DW (2017) Populations and activity patterns of clouded leopards and marbled cats in Dampa Tiger Reserve, India. 
J Mammal 98:1453-1462. https://doi.org/10.1093/jmammal/ gyx 104

Sunarto S, Kelly MJ, Parakkasi K, Hutajulu MB (2015) Cat coexistence in central Sumatra: ecological characteristics, spatial and temporal overlap, and implications for management. J Zool 296:104-115. https://doi.org/10.1111/jzo.12218

Sunquist ME, Sunquist F (2002) Wild cats of the world. University of Chicago Press, Chicago

Thinley P, Kamler JF, Wang SW, Lham K, Stenkewitz U, Macdonald DW (2011) Seasonal diet of dholes (Cuon alpinus) in northwestern Bhutan. Mamm Biol 76:518-520

Tsunoda H, Raichev EG, Newman C, Masuda R, Georgiev DM, Kaneko Y (2017) Food niche segregation between sympatric golden jackals and red foxes in central Bulgaria. J Zool 303:64-71
Valeix M, Chamaillé-Jammes S, Fritz H (2007) Interference competition and temporal niche shifts: elephants and herbivore communities at waterholes. Oecologia 153:739-748

Venkataraman AB (1995) Do dholes (Cuon alpinus) live in packs in response to competition with or predation by large cats? Curr Sci 69:934-936

Zar JH (1996) Biostatistical analysis, 4th edn. Prentice Hall, Upper Saddle River

Publisher's note Springer Nature remains neutral with regard to jurisdictional claims in published maps and institutional affiliations. 